\title{
The Wrong Prescription of Dialysis Fluid Thomas Ryzlewicz*
}

Dialysis Centre, ViaMedis Riesa, Germany

\section{Editorial}

The necessity of acidification has been recognised by Homer W. Smith (1929, "From Fish to Philosopher"). Because of the size of the mammalians and their high-turn-over metabolism, carbondioxide $\left(\mathrm{CO}_{2}\right)$ is transported in the body fluid as bicarbonate. To avoid calcification, there is a remnant of $\mathrm{CO}_{2}$, that is solved physically. The range of $\mathrm{CO}_{2}$ concentration is $40 \mathrm{~mm} \mathrm{Hg}$ resp. $1,2 \mathrm{mmol} / \mathrm{l}$. This acidification prevents the calcification of the ions with heavy solubility $\left(\mathrm{Ca}^{++}, \mathrm{Mg}^{++}\right.$and $\left.\mathrm{HCO}_{3}^{-}\right)$.

The treatment time of dialysis always has been relatively short compared to the time of living (> e.g. 3 x 5 hours per week in comparison to one week of living $(=168$ hours a week)). Consequently, protein feeding (consisting acids of phosphor and sulphate) results in metabolic acidosis. That is why the concentration of bicarbonate in dialysis fluid was elevated in all prescriptions to $32 \mathrm{mmol} / \mathrm{l}$ (instead of $24 \mathrm{mmol} / \mathrm{l}$ in the body fluid of healthy mammalians).

In 1978, acidification of bicarbonate containing dialysis fluid was set to $3 \mathrm{mmol} / \mathrm{l}$ acetate in most of all countries in the world. In France and in Japan higher concentrations of acetate are used consisting of 4 to $5 \mathrm{mmol} / \mathrm{l}$ acetate. Indeed the calcification of these dialysis fluids is lower, but there is another problem with $\mathrm{CO}_{2}$-overload generated in these patients, as the dialyzer has excellent facilities for gas exchange. A comparable disposable to the dialyzer is used in the cardio-pulmonary bypass for gas exchange. With the higher concentrations of acetate in the dialysis fluid patients with pulmonary problems (COLD, weaning from respirator breathing) do develop respiratory difficulties during dialysis. For this reason the prescription of dialysis fluid with acidification with $3 \mathrm{mmol} / \mathrm{l}$ acetate has been continued for 37 years up to now.

This particular prescription of bicarbonate dialysis fluid with 3 $\mathrm{mmol} / \mathrm{l}$ acetate causes severe problems of calcification. That is why the monitor must be descaled after every dialysis treatment. However, descaling of the patient has never been done(!) for well-known reasons, given the current situation of calcification by ingestion of inorganic phosphate containing nutrients.

To demonstrate the difficulties with handling this problem of acidification of bicarbonate containing dialysis fluid, the story of Dr. Bené (chemist, Hospal Company) will help. Bené was not successful to reach solubility in his bicarbonate dialysis fluid. That is why he achieved acidification by robbing the patient's own bicarbonate in performing dialysis fluid with a modified isotonic $\mathrm{NaCl}$-solution (= without any buffer!). The bicarbonate was given by infusion with an additional pump as Bag-HDF in a Low-Volume-Set-Up. The inability to handle this chemical problem of solubility resulted in a New Treatment (> AFB, Acetate Free Biofiltration) with the background of the inability to perform a real acidification (and nothing else). In the end, the AFB has never been really needed...
In contrast to a medical drug, dialysis fluid (resp. dialysis concentrate) has been classified a medical product. For a medical product just the CE label of the producer is sufficient and no studies are demanded. In the end, a producer of a medical product can do what he wants. Nobody will do a monitoring by a vigilance device concerning possible difficulties or problems, as this never has been taken into account(!). This is one reason why even the FDA is not particularly interested in this problem!

In the year 2012 a new prescription of bicarbonate dialysis fluid (A-Component as dialysis concentrate) has been delivered with acidification with $1 \mathrm{mmol} / \mathrm{l}$ citrate. Citrate is a threefold acid, so this prescription has the same acidification ( $>$ will say: the same amount of $\mathrm{CO}_{2}$-production) compared with the $3 \mathrm{mmol} / \mathrm{l}$ acetate concentrate. The important difference is, that with acidification with $1 \mathrm{mmol} / \mathrm{l}$ citrate there will be no calcification at all! That is why there is a second principle of working present, the chemical chelate binding between citrate and either heavy soluble Ions $\left(\mathrm{Ca}^{++}\right.$and $\left.\mathrm{Mg}^{++}\right)$. Working with citrate acidification, both problem ions being $\mathrm{Ca}^{++}$and $\mathrm{Mg}^{++}$respectively, will be disguised. This does prevent calcification sufficiently. You watch this particular falling out of calcification, when you open the fluid lines of the water compartment of a dialysis monitor even after a long-run test of 30 hours. The monitors never need descaling, when dialysis concentrate with citric acid has been used.

One should never forget, that CKD-5 patients do have a high cardiovascular risk of morbidity and of mortality concerning calcification (> coronary vessels, heart valves and peripheral arteries). A layman never would understand treating a patient with calcifying dialysis fluids (resp. concentrate) having an issue with calcifying problems anyway. As dialysis concentrates are medical products, it seems that everything is allowed hereby. . .

To summarize, there are two major problems in this context:

1. The ongoing ignorance of this issue by the supervising authority (FDA Dep. Medical Products)

2. The difficulty for medical doctors to understand the problem of chemical solubility in this setting. Even medical societies did not realise this.

The perspective: publishing this issue in order to involve the Ministry of Health to get the FDA to work on this. First target should be to induce a chemical-evaluation, second target should be a prohibition of dialysis concentrates with $3 \mathrm{mmol} / \mathrm{l}$ acetate.

*Corresponding author: Thomas Ryzlewicz, Senior Consultant Nephrologist, Dialysis Center, ViaMedis Riesa, Robert-Koch-Strasse 30, D-01589, Riesa Germany, Tel: +49 17283666 25; E-mail: thomas.ryzlewicz@web.de

Received: July 11, 2015; Accepted: July 12, 2015; Published: July 19, 2015

Citation Ryzlewicz T (2015) The Wrong Prescription of Dialysis Fluid. J Nephrol Ther 5: e113. doi:10.4172/2161-0959.1000e113

Copyright: () 2015 Ryzlewicz T. This is an open-access article distributed under the terms of the Creative Commons Attribution License, which permits unrestricted use, distribution, and reproduction in any medium, provided the original author and source are credited. 